1 Tyndall A, Gratwohl A. Haemopoietic stem and progenitor cells in the treatment of severe progenitor cells in the treatment of severe 55:149-51.

2 Jacobs P, Vincent MD, Martell RW. Prolonged remission of severe refractory rheumatoid arthritis following allogenic bone marrow transplantation for drug induced aplastic anaemia. Bone Marrow Transpl 1986;1:237-9.

3 Lowenthal RM, Duhlen ML, Atkinson K, Biggs JC. Apparent cure of rheumatoid arthritis by bone marrow transplantation. $f$ Rheumatol 1993;20:137-40.

4 Brugger W, Heimfeld S, Berenson RJ, Mertelsmann $R$, Kanz $L$. Reconstitution of haematopoiesis after high dose chemotherapy by opoiesis after high dose chemotherapy by autologous progenitor cells gen

5 Marmont AM, Tyndall A, Gratwohl A, Vischer Marmont AM, Tyndall A, Gratwohl A, Vischer
T. Haemopoietic precursor-cell transplants for T. Haemopoietic precursor-cell transplants for
autoimmune diseases. Lancet 1995;345:978.

\section{The association between fibromyalgia and carpal tunnel syndrome in the general population}

Fibromyalgia and carpal tunnel syndrome are common diseases in adult women. Their prevalences in the whole population are $2 \%^{1}$ and $9.2 \%,{ }^{2}$, respectively. Recently, a study performed in northern Spain has suggested that the two conditions are often associated, with 33 of 206 outpatients with fibromyalgia showing evidence of carpal tunnel syndrome. $^{3}$ This $16 \%$ prevalence for the association is higher than that observed for carpal tunnel syndrome alone and suggests that common underlying mechanisms are at work. However, the study was done on patients referred to the clinic for fibromyalgia and no data are known about the occurrence of the association in the general population. During a survey on the prevalence of peripheral pain in an Italian population sample, we came across several patients with fibromyalgia or carpal tunnel syndrome and have studied the occurrence of the association between the two conditions.

A postal questionnaire ${ }^{4}$ was sent to 4456 subjects living in Chiavari, northern Italy, to investigate the presence of articular signs and symptoms. Individuals were asked to report if they had any joint pain or swelling for more than four continuous weeks and if they currently had joint pain or swelling, by indicating the relevant sites on a mannequin. In addition, they were asked to report the presence of morning stiffness lasting more than 30 minutes. This set of questions was originally developed by the ARC Epidemiology Unit in Manchester, United Kingdom ${ }^{4}$ and its primary goal was to detect prevalent cases of rheumatoid arthritis.

The diagnosis of fibromyalgia was based on the criteria suggested in 1990 by the American College of Rheumatology ${ }^{5}$, that is, widespread pain and the presence of tenderness in at least 11 of 18 sites (tender points).
The diagnosis of carpal tunnel syndrome was made on clinical grounds. It included (a) history of numbness, paraesthesia, and/or pain in the fingers innervated by the median nerve, and (b) positive Tinel sign or positive Phalen sign. Invasive tests, such as nerve conduction studies, were not performed in view of the epidemiological nature of the research.

After two mailings, 2440 out of 4456 subjects $(54.8 \%)$ returned the questionnaire. Of these, $182(7.5 \%)$ had joint pain and swelling in at least two joints. This group of patients was offered a clinical examination; 93 (51.1\%) agreed to be visited. Fibromyalgia was present in $21(22.6 \%)$ of these patients and carpal tunnel syndrome in $26(28 \%)$. Both conditions occurred simultaneously in nine patients $(9.7 \%)$ (table). The odds ratio for patients with any one of the conditions of showing the other one was $2.4 \quad(95 \%$ confidence interval 0.9 to 6.8 ). These fibromyalgia-carpal tunnel syndrome patients were all female, whereas $23.5 \%$ of patients with carpal tunnel syndrome were male. What is more, if only women with carpal tunnel syndrome or fibromyalgia are considered, nearly half of them also had the other disease. The mean number of tender points was obviously higher in patients with fibromyalgia than in those with carpal tunnel syndrome alone $(13.2 v 3.8 ; \mathrm{P}<0.001)$. Self reported joint swelling and early morning stiffness were similarly distributed in the three groups of patients.

Our data show that responders who reported a history of joint pain and swelling of peripheral joints were often affected by fibromyalgia or carpal tunnel syndrome. This study does not disclose the absolute prevalence of fibromyalgia and carpal tunnel syndrome because the questionnaire was intended for screening patients with possible rheumatoid arthritis and not those with fibromyalgia or carpal tunnel syndrome. However, in a pilot study, most of the outpatients with these conditions attending a rheumatological clinic answered positively to the questionnaire. We believe that patients with fibromyalgia reported articular involvement on the mannequin because they were unable to differentiate articular from extra-articular pain. In addition, they frequently overreported swelling. Patients with carpal tunnel syndrome as a rule complain of pain and numbness associated with a subjective sensation of swelling in the hands, especially in the morning. Both fibromyalgia and carpal tunnel syndrome are characterised by morning stiffness.

In addition, there is the possibility of a selection bias due to over-representation of patients with more severe conditions, since this subgroup is more likely to respond to questionnaires. A further limitation of this study was that the same observer performed the Tinel and Phalen tests and pressed tender points. Therefore, information bias cannot be excluded. Both biases would increase the strength of this association. Nevertheless we feel that the magnitude of the association between fibromyalgia and carpal tunnel syndrome in the general population showed by our study should prompt further investigation on possible similarities in the aetiopathogenic mechanisms at work in these conditions.

MARCO A CIMMINO MARIA PARISI GIANLUIGI MOGGIANA SILVANO ACCARDO

Cattedra di Reumatologia DIMI, Università di Genova, Viale Benedetto XV, 6, 16132 Genova

1 Wolfe F, Ross K, Anderson J, Russel IJ, Herber $\mathrm{L}$. The prevalence and characteristics of fibromyalgia in the general population. Arthritis Rheum 1995;38:19-28.

2 De Krom MCTFM, Knipschild PG, Keste ADM, Thus CT, Boekkoi PF, Spaans F. Carpal tunnel syndrome: prevalence in the general population. F Clin Epidemiol 1992, 45:373-6.

3 Perez-Ruiz F, Calabozo M, Alonso-Ruiz A Herrero A, Ruiz-Lucea E, Otermin I High prevalence of undetected carpal tunnel Hyntunnel syndrome in patients with fibromyalgia syndrome 7 Rheumatol 1995;22:501-4.

4 MacGregor AJ, Riste LK, Hazes JMW, Silman AJ. Low prevalence of rheumatoid arthritis in Black-Caribbeans compared with Whites in innner city Manchester. Ann Rheum Dis 1994 53:293-7.

5 Wolfe F, Smythe HA, Yunus MB, et al. The American College of Rheumatology 1990 criteria for the classification of fibromyalgia: report of the Multicenter Criteria Committee. Arthritis Rheum 1990;33:160-72.

\section{Correction}

In the paper by Torre $e t$ al in the August issue ("Antibodies to ribosomal $\mathrm{P}$ proteins ...", p 562), the authors' names were printed in the wrong order. The order should have been; J C Torre, L Mozo, A Suárez, E Ramos, C Gutiérrez.

Demographic and clinical characteristics of the patients, expressed as means and $95 \%$ confidence intervals (CI)

\begin{tabular}{llll}
\hline & Fibromyalgia & $\begin{array}{l}\text { Carpal tunnel } \\
\text { syndrome }\end{array}$ & Both \\
\hline Number & 12 & 17 & 9 \\
Men/women & $1 / 11$ & $4 / 13$ & $0 / 9$ \\
Mean age (years (SD)) & $58.7(15.5)$ & $51.8(14.6)$ & $51.3(12.9)$ \\
Mean number of tender points & $13.4(11.8-15)$ & $3.8(2.6-5.1)$ & $13(11.1-14.9)$ \\
Mean duration of morning stiffness (min) & $65.7(23.2-108.2)$ & $44.5(25.7-63.3)$ & $31.4(15.7-47.1)$ \\
$\begin{array}{l}\text { Mean number of joints reported as } \\
\quad \text { swollen }\end{array}$ & $5.8(3.5-8.1)$ & $3.8(2.9-4.7)$ & $4.9(2.3-7.5)$ \\
& & & \\
\hline
\end{tabular}

